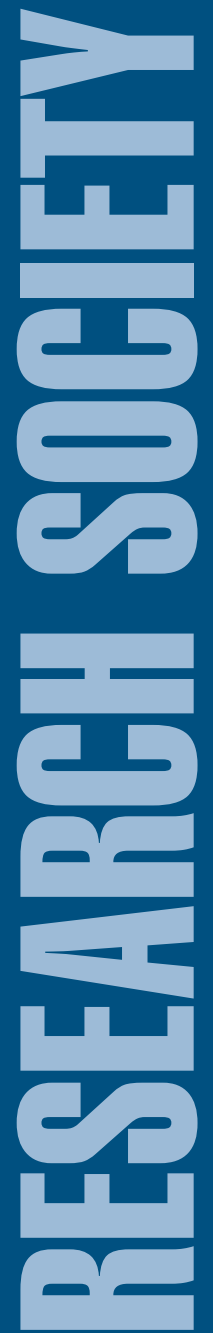

\author{
Having perspectives and ideas from industry enhances the quality and value \\ of our offerings for all MRS members.
}

\title{
The MRS mission and industry
}

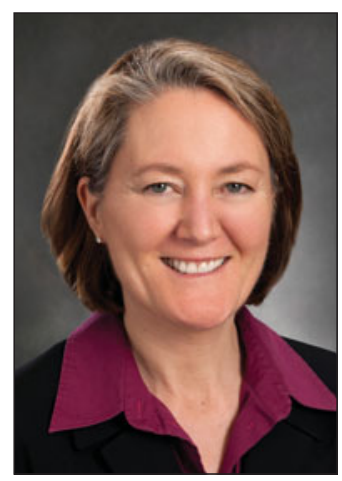

Tia Benson Tolle 2014 MRS President

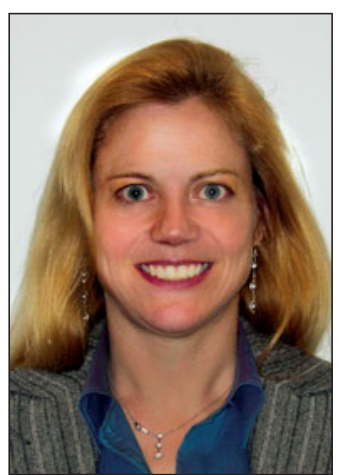

Shenda Baker

Chair, MRS Planning

Committee
During the Materials Research Society Board of Directors' multi-year effort to chart the future of MRS meetings, we recognized that the number of industrial attendees was decreasing, and our current members would benefit by re-engaging that segment of the materials research community. In the early years, MRS meetings attracted researchers from all sectors, including over a third of the attendees coming from industry. Today, that participation is around 10 percent.

The MRS Planning Committee was commissioned to chart a path forward to better engage materials researchers from industry, with clear guidance not to focus on numbers (e.g., attendees, membership), but on fulfilling MRS's Mission and Vision of building a community of researchers from all sectors of the materials community around the world. The committee was asked to evaluate how the Society as a whole (meetings, publications, outreach, and advocacy) can better serve industries of all sizes. The committee also considered how greater industrial engagement would add value to our current membership.

To understand how MRS could increase its value to industry, the Planning Committee reached out to members and non-members in industry. We also surveyed current members about how increased industrial participation would benefit them. Some key findings included:

- Cross-sector communication is needed to exchange ideas and discuss needs.

- There is desire to engage. The idea of MRS expanding the "cross-sector community" had much resonance. Many of the interviewed people not only provided feedback, they also jumped in to help us formulate a path forward.

- Don't dramatically change MRS; continue MRS's commitment to highquality research.

During the 2013 MRS Fall Meeting, the Board issued a Strategic Intent for MRS Engaging Industry to guide volunteers and staff as they develop new programs and evolve existing ones. 
We would like to emphasize our core MRS values as we close this letter. We're not seeking to dramatically change MRS, nor are we looking to develop industry-related efforts in isolation. Instead, we'd like to enhance the early MRS vision of serving academia, industry, and national and private laboratory researchers by facilitating vital interactions among all sectors of the community for the good of all in a manner that is consistent with the current technology and the current needs of industry.

To achieve these goals, one important step will be to involve industrial members in MRS governance, and specifically the operating committees, the engines behind the invaluable programs and products of the Society. Having perspectives and ideas from industry can only enhance the quality and value of our offerings for all MRS members. Our engagement of all communities in the materials field is the best way to maintain MRS's focus on high-quality materials research, to ensure that MRS programs meet the needs of all sectors, and to build our community.

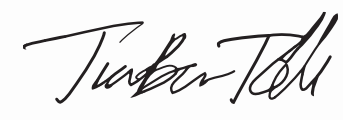

Tia Benson Tolle

2014 MRS President

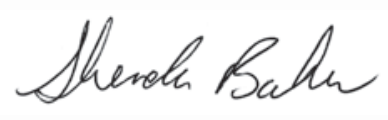

\section{Shenda Baker}

Chair, MRS Planning Committee

\section{Strategic Intent for MRS Engaging Industry}

MRS will engage and support materials scientists and engineers from industries worldwide to fulfill our Mission and Vision of building a community of materials researchers from all disciplines and all sectors. We will do so by adhering to our Core Values (http://www.mrs.org/mission-vision-values/) and by

- promoting excellence in materials research, development, and applications to improve the quality of life,

- fostering innovation by connecting people and their ideas,

- facilitating networking across all employment sectors and disciplines worldwide, and

- engaging MRS members from industry in MRS meetings, publications, advocacy, outreach, and governance.

\section{Interested in helping MRS Committees move the Vision forward?}

Please contact Michele Feder, Manager-Volunteer Affairs, at feder@mrs.org 


\section{GIII CheMTSTYY OF}

\section{Celebrating 25 Years \\ of Chemistry of Materials}

CIIT MATERPALIS

JANUARY 14, 2014 | VOLUME 26 | NUMBER 1 | pubs.acs.org/cm

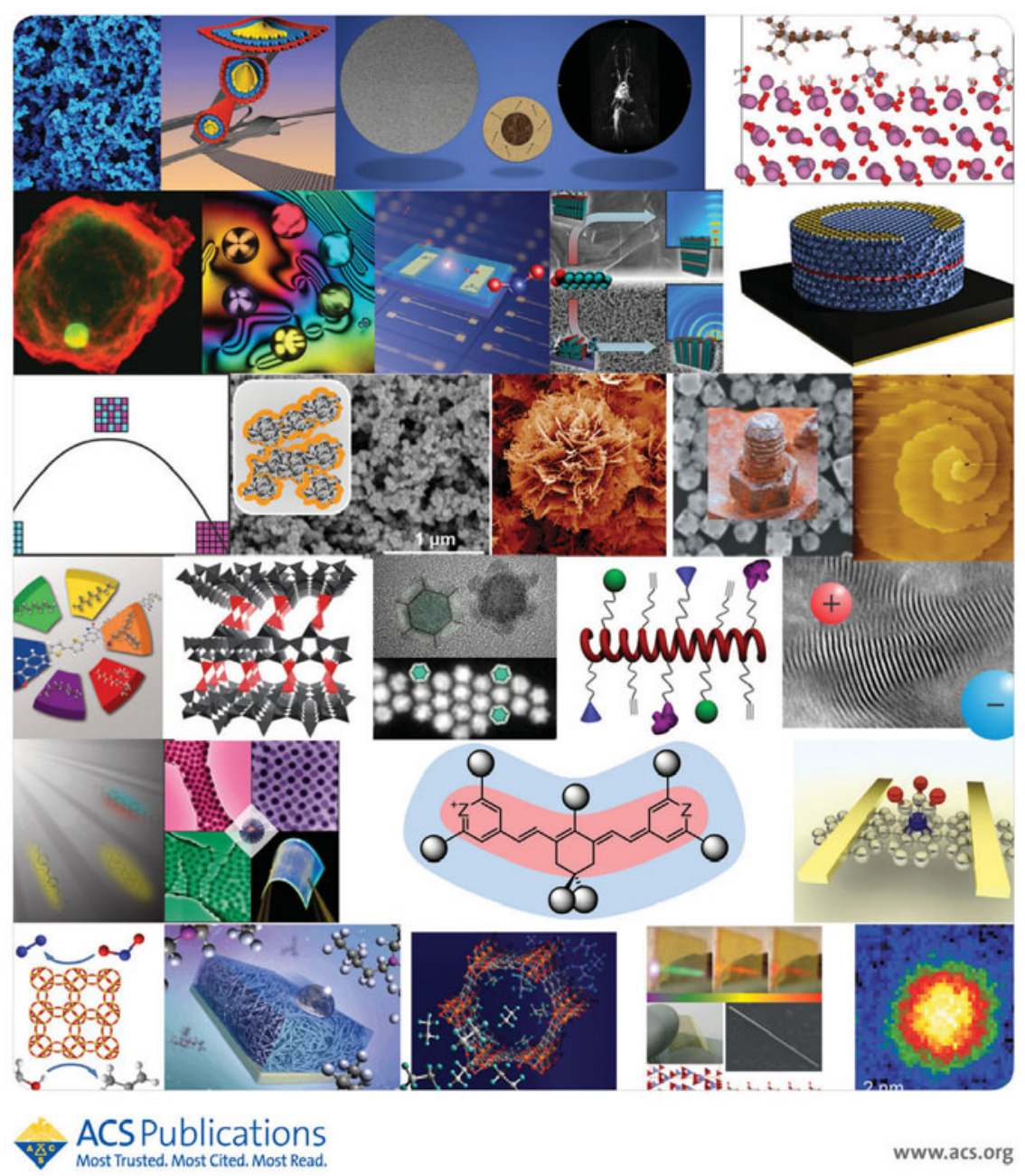




\section{ACS Publications}

FOUNDING EDITOR-IN-CHIEF

Leonard V. Interrante

Rensselaer Polytechnic

Institute, New York

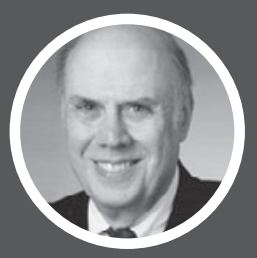

SPECIAL ISSUE CO-EDITOR

Edwin A. Chandross

Materials Chemistry LLC

Murray Hill, New Jersey

\section{SPECIAL ISSUE:}

\section{Celebrating 25 Years of Chemistry of Materials}

This Special Issue celebrates 25 years of publication for Chemistry of Materials. It contains 66 invited and peer-reviewed Reviews and Perspectives from an international group of authors representing a broad range of disciplines. This Issue provides an exceptionally wide spectrum of topics that cover a range of materials types and applications, representative of the scope of materials chemistry research in the 21st century.

\section{Topics Covered in Reviews and Perspectives}

- This Special Nanoparticle Synthesis, Growth, and Applications

- Nanostructured Carbon Materials

- Nanoporous Materials

- Energy Storage and Conversion
- Organic Materials in Electronics and Photonics

- Surfaces, Interfaces, and Coatings

- Inorganic Materials

\section{Go to pubs.acs.org/cm}

